\title{
Trans and cis requirements for intron mobility in a prokaryotic system
}

\author{
Jonathan Clyman and Marlene Belfort ${ }^{1}$ \\ Molecular Genetics Program, Wadsworth Center for Laboratories and Research and School of Public Health, State \\ University of New York, New York State Department of Health, Albany, New York 12201-0509 USA
}

\begin{abstract}
Intron mobility requires cleavage of an intronless allele by an intron-encoded endonuclease, followed by transfer of the intron into the cleaved recipient. The mobile phage introns provide an opportunity to identify accessory functions involved in the intron inheritance process. To test for trans and cis requirements of mobility in Escherichia coli, we have exploited the $t d$ intron of phage T4 in both phage T4 and $\lambda$ genetic backgrounds. Mobility depends on host or phage recombinase functions, RecA or UvsX, respectively. The process also requires a phage-encoded $5^{\prime} \rightarrow 3^{\prime}$ exonuclease activity and associated annealing function that can be provided by phage $\lambda$. Finally, host-encoded $3^{\prime} \rightarrow 5^{\prime}$ exonuclease activities are also implicated in intron inheritance. We demonstrated further that restriction enzymes could substitute for the intron-encoded endonuclease, indicating that the endonuclease does not have an essential role in recombination. Neither the precise position nor the nature of the double-strand break was critical to intron transfer. These features provide insight into the recombination pathway and are factors impacting on the spread of introns throughout natural populations
\end{abstract}

[Key Words: Phage T4; phage $\lambda_{;} t d$ intron endonuclease; RecA and UvsX recombinases; $5^{\prime} \rightarrow 3^{\prime}$ exonuclease; $3^{\prime} \rightarrow 5^{\prime}$ exonuclease]

Received March 12, 1992; revised version accepted April 24, 1992.

Mobile group I introns have been identified in a diverse range of prokaryotic and lower eukaryotic species (for review, see Dujon 1989; Lambowitz 1989; Clyman et al. 1992). Interestingly, group I introns showing a high degree of similarity appear in different locations in species that are not closely related, fueling arguments that introns crossed species lines (Michel and Dujon 1986; Lambowitz 1989|. Furthermore, common features of the mobility process suggest that compatible trans-species mechanisms exist for acquiring and propagating mobile introns. It is therefore of interest to define precisely the recombination events that result in intron inheritance and to determine which accessory recombination and/or repair functions are required for mobility. Analogous functions would be predicted to exist in those organisms that host mobile introns, whereas the absence of such functions would be expected to present a barrier to mobile introns colonizing that biological system.

Mobility of group I introns is defined as the conversion of an intron-minus ( $\left.\operatorname{In}^{-}\right)$allele to intron-plus $\left(\mathrm{In}^{+}\right)$. The process depends on a double-strand break (DSB) introduced into the intron recipient by an intron-encoded endonuclease (Dujon 1989; Lambowitz 1989; Perlman and Butow 1989; Belfort 1990). The ensuing recombination events, thought to proceed via the double-strand-breakrepair (DSBR) pathway (Szostak et al. 1983), result in

${ }^{1}$ Corresponding author. unidirectional transfer of the intron to the cleaved "homing" site (Dujon et al. 1989) (Fig. 1). This pathway, as originally proposed (Szostak et al. 1983), has the DSB processed into a gap with the concomitant formation of exposed $3^{\prime}-\mathrm{OH}$ tails to both initiate strand invasion and serve as primers for repair synthesis. With an introncontaining donor duplex as template, this will result in transfer of the intron to the cleaved recipient.

The mobile phage introns provide an opportunity to assess the involvement of host and phage functions in intron inheritance and to probe the cis requirements for DSB-initiated recombination. Using the phage system, we have demonstrated that specific $t d$ intron sequences are not required for mobility if the intron-encoded endonuclease (I-TevI) is supplied in trans (Bell-Pedersen et al. 1990). The availability of well-characterized phage and host mutations in DNA recombination and repair genes allows investigation of the role of corresponding functions in the mobility event and facilitates further definition of cis requirements.

Three different experimental systems are used in this study. Phage $\lambda$ is the model system for several analyses because it offers a number of advantages over T4: First, unlike T4, $\lambda$ does not degrade host DNA, simplifying the recovery of plasmids from infected cells. Second, because of its smaller genome and unmodified DNA, $\lambda$ is more amenable to genetic and in vitro manipulation. Third, $\lambda$ has a simpler and better-defined recombination system 


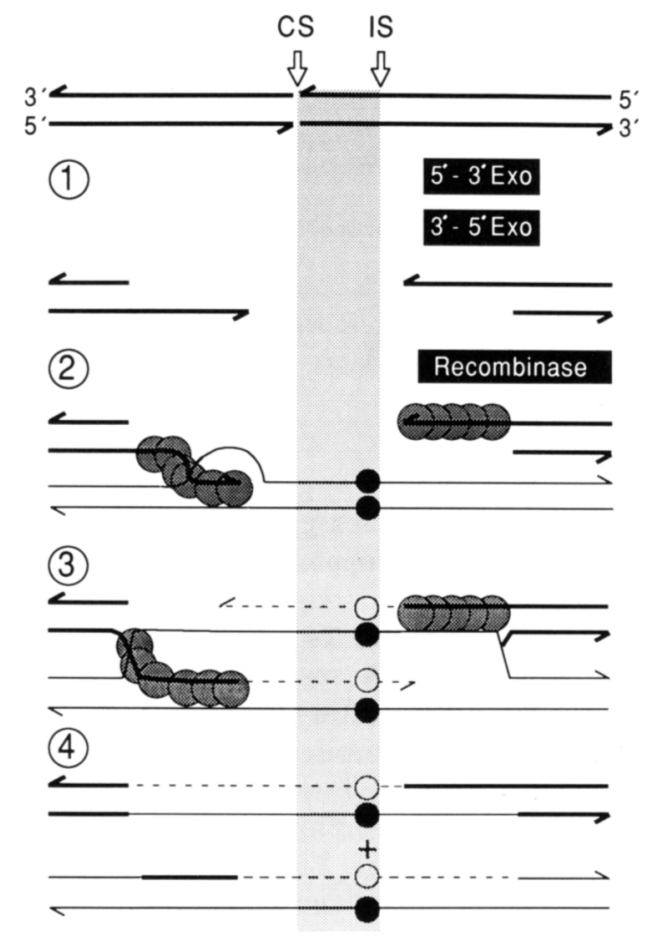

Figure 1. The DSBR pathway for intron mobility with implicated accessory functions. The model of Szostak et al. (1983) is adapted to the $t d$ intron, with the cleavage site (CS) upstream of the intron insertion site (IS). (Step 1) Resection of DNA ends and 3 ' single-stranded tail formation by requisite exonuclease activities. Vertical shading represents the requirement for gap formation. (Step 2) Binding of recombinase to $3^{\prime}$ tails, strand invasion, and melting of the donor duplex. Recombinases RecA ( $E$. coli), Bet ( $\lambda$, associated with Exo), and UvsX (T4) have been implicated. Their relative roles remain speculative (see Discussion). (Step 3) Recombinase-mediated annealing of homologous exons, D-loop formation, and repair synthesis. (Step 4) Ligation and resolution of Holliday junctions in the non-cross-over configuration. (Thick line) Recipient; (thin line) donor; (broken line) new DNA; (overlapping stippled circles) recombinase; (solid circle) original intron; (stippled circle) new intron.

than T4, and its recombination genes are clustered. Finally, unlike $T 4$, the recombination functions of $\lambda$ are dispensable for phage viability, facilitating the analysis of recombination-deficient mutants. With information gained about requirements for mobility from the $\lambda /$ Escherichia coli system, it was possible to address specific questions utilizing T4 as the model organism. Furthermore, knowledge acquired from the $\lambda$ experiments allowed us to establish an intron mobility system in uninfected cells. With this phage-free system, other requirements of the gene conversion process were tested.

Utilizing these model systems we show that transfer of the $t d$ intron is promoted by a combination of host and phage functions: recombinases $(E$. coli RecA or $\mathrm{T} 4$ UvsX), as well as $5^{\prime} \rightarrow 3^{\prime}$ and $3^{\prime} \rightarrow 5^{\prime}$ exonucleases. We also demonstrate that gene conversion occurs independently of I-TevI, provided that the recipient has been cleaved in sequences homologous to the intron donor.
The process also proceeds regardless of whether cleavage of the recipient generates staggered or blunt ends. That is, neither the nuclease that promotes the mobility event nor the precise nature of the DNA ends appears to impact directly on recombination. These properties are described in terms of recombination pathway and with regard to the ability of introns to invade prokaryotic genomes.

\section{Results \\ Intron homing in the absence of $T 4$ infection requires host $\operatorname{Rec} A$ function}

Phage $\lambda$ containing the $t d$ intron homing site ( $\lambda t d \Delta \mathrm{In}$ ) can act as recipient for the $t d$ intron, efficiently acquiring the intron in cells carrying an intron-donor plasmid (Quirk et al. 1989). We have applied this assay, described in Figure 2, to screen hosts defective in functions involved in different DNA repair and recombination pathways. Of the mutants screened, only the RecA-deficient host had a striking effect on mobility (Fig. 2). Mutants used are described in Table 1. Intron inheritance was virtually unaffected by mutations in site-specific recombination functions, in the fis, him $A$, hup $A$, and hup $B$ alleles (Fig. 2A), or in general recombination genes, recl, $\operatorname{recN}$, and $r u v B$ (Fig. 2B). Whereas there was a modest 2to 4-fold reduction in the $\operatorname{rec} B C$ and $\operatorname{rec} F$ hosts, respectively, there was a 500-fold decrease in mobility in the $\operatorname{rec} A$ host. This sharp reduction in frequency of intron inheritance under $\operatorname{rec} A^{-}$conditions indicates a critical role for RecA in intron homing.

In addition to being the primary recombinase in $E$. coli, RecA is the positive activator of the SOS response. RecA cleaves LexA, the repressor of the SOS regulon, in response to DNA damage, leading to expression of DNA repair functions (Walker 1984). Because SOS is induced in cells expressing I-TevI (D. Bell-Pedersen, unpubl.), we tested whether the requirement for RecA might be the result of its role in SOS induction. When intron mobility was tested in a lex $A 3$ host, which produces a noncleavable LexA repressor, no difference was observed compared with the lex $A^{+}$control (Fig. 2C). These results indicate that the RecA requirement for homing is not the induction of an SOS function; rather, they implicate the role of the recombinase function of RecA. The dependence of intron mobility on a RecA-like recombinase is consistent with the requirement for exon homology in efficient homing (Quirk et al. 1989) and with the presumed need for strand invasion in the DSBR model for intron inheritance (Fig. 1).

\section{T4 can complement the $\operatorname{Rec} A$ requirement for intron homing-a role for UVsX}

To assess whether phage $\mathrm{T} 4$ provides functions that complement the role of RecA, we monitored intron mobility in T4-infected cells, taking advantage of the transducing capacity of T4 (Wilson et al. 1979; Kreuzer and Alberts 1986). Intron acquisition into recipient plasmid 
Table 1. Bacterial and phage strains

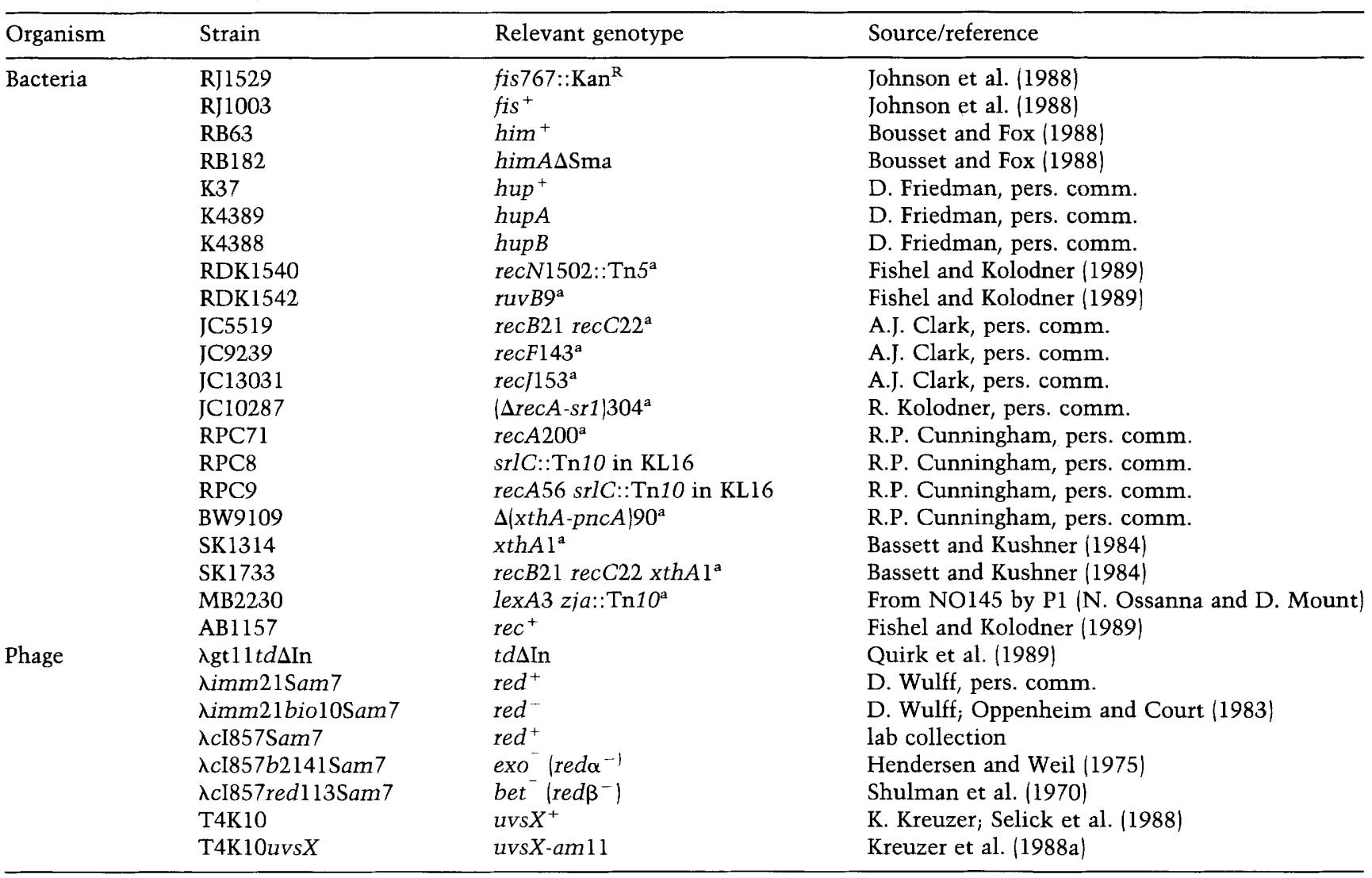

In AB1157 background, thr-1 leuB6 $\Delta$ (gpt-proA|2 hisG4 argE3 thi-1 ara-14 lacYl galK2 xyl-5 mtl-1 rpsL31 tsx-33 supE44 (rac).

DNA packaged by $\mathrm{T} 4$ was probed in transductants that inherited the plasmid from defective progeny phage (Fig. $3 \mathrm{~A}, \mathrm{~B})$. Plasmids are described in Table 2. Efficient intron homing was observed in both $r e c A^{+}$and $r e c A^{-}$cells (Fig. 3B, crosses 1 and 2, respectively). However, when cleavage was prevented by using a recipient with a 10-bp insert at the intron insertion site ( $t d \Delta \operatorname{In} 10 \mathrm{r})$, homing was abolished (Fig. 3B, cross 3), indicating that recombination is absolutely dependent on a DSB. Over four trials, the average intron inheritance frequency among the transductants was $50.7 \% \pm 1.7 \%, 42.5 \% \pm 1.3 \%$, and $0.2 \% \pm 0.6 \%$ for crosses 1,2 , and 3 , respectively (Fig. $3 \mathrm{~B})$. Restriction analysis of plasmid DNA from In ${ }^{+}$ transductants showed the pattern of DNA fragments diagnostic of insertion of the $t d$ intron into its homing site (Fig. 3C). These results demonstrate that T4-mediated intron mobility can occur in the absence of host RecA function and that $\mathrm{T} 4$ functions satisfy the requirement for recombinase activity predicted by the DSBR model.

The T4-encoded uvs $X$ gene product is a recombinase that is functionally similar to RecA (Yonesaki et al. 1985; Formosa and Alberts 1986) and might thus have a role in T4-mediated intron homing. To test for a UvsX requirement in the mobility reaction, we performed Southern analysis on DNA isolated from T4uvs $X$-infected cells and probed for intron acquisition by recipient plasmids (Fig. 4). A dependence on UvsX was reflected in the appearance of intron-containing recombinant plasmids, after EcoRV digestion, when the infecting phage was uvs $X^{+}$(Fig. 4, lanes $1,3,8$ ) but not when the phage was uvs $X^{-}$(Fig. 4, lanes 2,4). This was true irrespective of whether cells were $r e c A^{+}$(Fig. 4, lanes $1,2,8$ ) or $r e c A^{-}$ (Fig. 4, lanes 3,4). This latter result is consistent with the finding that RecA is inactive during T4 infection, rendering general recombination in infected cells dependent on the UvsX function (Yonesaki and Minagawa 1988). The intron-containing bands were not evident when the recipient contained a disrupted homing site (Fig. 4, lane $5)$, indicating that this UvsX-dependent recombination event requires a DSB. Furthermore, the only band that disappeared upon digestion with $H$ haI, which cleaves only unmodified (i.e., unreplicated) DNA, is the recipient (pSUtdsIn-r) band (Fig. 4, lane 8; more evident on darker exposure). This result suggests that homing took place into replicating DNA or that homing occurred into DNA that subsequently replicated.

Because plasmids that have homology to $\mathrm{T} 4$ replicate in a UvsX-dependent manner (Kreuzer et al. 1988b), it was important to distinguish between a UvsX requirement for homing versus replication. We therefore used recipient plasmids containing a $\mathrm{T} 4$ tertiary replication origin, which renders T4-driven replication of plasmids 
Figure 2. Screening of host factors required for intron mobility. Results of crosses depicted in the diagram (left) are presented in the table (right). Cells, either mutant $(-)$ or wild type $(+)$ at the locus indicated (Table 1), were lysogenized with the recipient (R) $\lambda$ gtlltdd In and transformed with the intron donor (D) plasmid pKTd2 containing the $t d$ gene under $\lambda p_{\mathrm{L}}$ control (Table 2). Homology between the $R$ and $D$ alleles in all crosses in this study is above the limit required for efficient homing (Quirk et al. 1989), at $\sim 800$ nucleotides for each exon. After induction, progeny phage were probed for intron inheritance /see Materials and methods). An average of 800 plaques was probed for each cross. Relative frequency represents intron inheritance in the mutant relative to the isogenic wild-type host. Percent homing was corrected for background recombination by use of a donor control deleted for the endonuclease-encoding ORF (pKTd $\Delta 1-3$ ) for each host $(0.1-0.5 \%)$. The thermosensitive
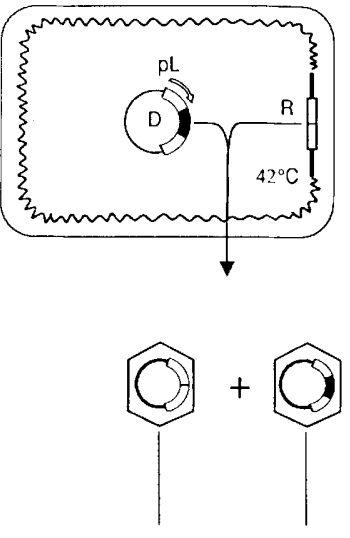

\begin{tabular}{llccc}
\hline & $\begin{array}{c}\text { Gene } \\
\text { locus }\end{array}$ & \multicolumn{2}{c}{ \% Homing } & $\begin{array}{c}\text { Relative } \\
\text { freq } /+\end{array}$ \\
\hline A & fis & 46.2 & 41.7 & 0.90 \\
& himA & 31.3 & 33.2 & 1.06 \\
& hupA & 40.4 & 60.4 & 1.49 \\
& hupB & 40.4 & 57.4 & 1.42 \\
& & & & \\
B & recA & 61.9 & 0.1 & 0.002 \\
& recBC & 21.6 & 10.9 & 0.50 \\
& recF & 26.7 & 6.6 & 0.25 \\
& recJ & 26.7 & 30.0 & 1.12 \\
& recN & 69.2 & 66.8 & 0.97 \\
& ruvB & 69.3 & 64.3 & 0.93 \\
& & & & \\
C & lexA3 & 21.6 & 20.1 & 0.93
\end{tabular}

recA200 allele of $r e c A$ was used because I-TevI-containing transformants could not be maintained in an unconditional recA host. (Thick line) Phage DNA; (thin line) plasmid; (wavy line) cellular DNA; (open rectangle) exon; (solid rectangle) intron.

independent of UvsX (Kreuzer et al. 1988a). Again, intron inheritance was dependent on UvsX function (Fig. 5). After digestion with $S s p I$ (which was used in this experiment because it cleaves T4-modified DNA more completely than does $E c o R V$ ), the intron-containing band appeared only when infecting phage were uvs $X^{+}$(Fig. 5, lanes 1,3 ), regardless of whether cells were $r e c A^{+}$(Fig. 5, lanes 1,2 ) or rec $A^{-}$(Fig. 5, lanes 3,4). Thus, in a system in which plasmid replication is independent of UvsX, intron transfer still requires UvsX function, arguing that the UvsX requirement for mobility reflects a direct role for this protein in recombination.

\section{$\lambda$-Encoded factors required for intron mobility}

Uninfected $E$. coli appears unable to support intron mobility even in $r e c A^{+}$cells. Whereas the $t d$ intron is capable of homing from a plasmid donor to T4tdsIn or $\lambda t d \Delta \mathrm{In}$, intron transfer is undetectable from a plasmid donor to a plasmid recipient (Quirk et al. 1989; Fig. 6, cross 1). To test the involvement of phage functions in mobility, we again resorted to the $\lambda$ system, for reasons indicated in the introductory section. We thus probed plasmid-to-plasmid intron homing in the presence of a wild-type $\lambda$ helper phage. Recombination-proficient $\lambda$ promoted efficient (18.7-19.7\%) intron homing (Fig. 6, crosses 2 and 5). Consistent with a stimulation of DSBdependent recombination by the $\lambda$ helper, recombination dropped to background levels $(<0.5 \%)$ when the donor plasmid was deleted in the intron open reading frame (ORF), which encodes the homing site-specific endonuclease required for mobility (Quirk et al. 1989; Belfort 1990; Clyman et al. 1992) (Fig. 6, cross 3). Likewise, when $\mathrm{ORF}^{+}$transformants were infected with $\lambda$ bio 10 , in which the phage recombination region is deleted, intron mobility was eliminated (Fig. 6, cross 4), indicating that $\lambda$ recombination functions are necessary for intron homing in this system.

Because the $\lambda$ Red recombination pathway is stimulated by double-strand cuts within regions of homology, resulting in gene conversion events (Thaler et al. 1987a), we examined mutations in the red genes /deleted in $\lambda$ biolo) to determine whether these are the phage functions that act to promote mobility. We probed a role for Exo, the red $\alpha$-encoded $5^{\prime} \rightarrow 3^{\prime}$ exonuclease that processively degrades double-stranded DNA, and Bet, the $\operatorname{red} \beta$ encoded Exo-associated annealing activity, in intron inheritance. Infection of plasmid-containing cells with phage defective in either red $\alpha$ or red $\beta$ resulted in a sharp decrease in intron mobility (Fig. 6, crosses 6 and 7), supporting a role for Exo and Bet in mobility. This requirement for Red functions mirrors that for homology-dependent double-strand gap repair in E. coli (Takahashi and Kobayashi 1990), supporting a straightforward DSBR mechanism for mobility in favor of an intron-specific recombination pathway. Corroborative data are provided by Eddy and Gold (1992) with an artificial mobile intron constructed with the EcoRI endonuclease and methylase genes. Thus, the EcoRI intron could be mobilized at levels comparable to authentic mobile introns upon induction of $\lambda$ Red functions.

\section{Probing the roles of $5^{\prime} \rightarrow 3^{\prime}$ exonuclease} and annealing functions

Because mobility did not drop to background levels with the $\lambda r e d$ mutants (Fig. 6 , cf. cross 4 with 6 and 7), it was unclear whether Exo and Bet are sufficient to promote intron transfer. We therefore developed a three-plasmid mobility system using the cloned $\lambda$ Red genes (Fig. 7A). In these experiments the $\mathrm{Cam}^{\mathrm{R}}$ recipient plasmid is cleaved in vitro with I-TevI and then transformed into cells car- 
A

B

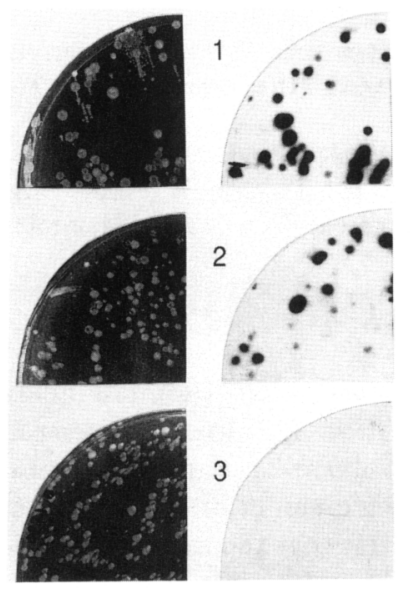

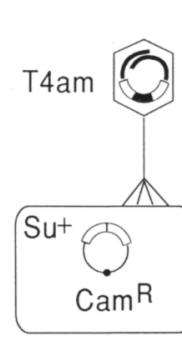

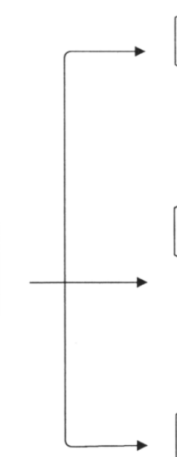

1
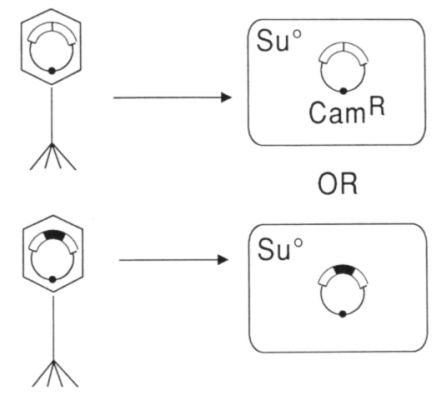

C
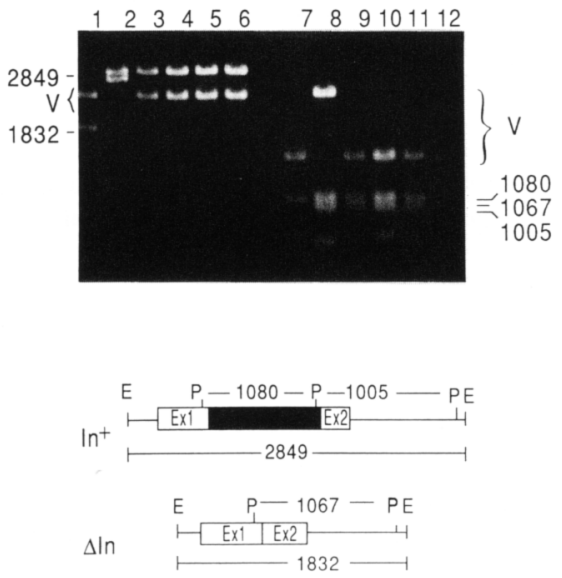

Figure 3. T4-mediated intron mobility in a recA host. (A) Schematic representation of the T4 transduction assay for intron mobility. Cam ${ }^{\mathrm{R}}$ transductants arising from delivery of plasmid DNA by T4transducing particles were selected on $\mathrm{Su}^{\circ}$ cells, which cannot support growth of defective intron donor phage T4K10. (Thick line) Phage DNA; (thin line) plasmid DNA; (open rectangle) exon; (solid rectangle) intron. $(B)$ Transduction assay. Transductants (left) from crosses in $\mathrm{AB} 1157\left(\mathrm{rec}^{+}\right)$/ pSUtd $\Delta$ In-r (1), JC10287(rec $\left.A^{-}\right) /$pSUtd $\Delta$ In-r (2), or $\mathrm{AB} 1157\left(\mathrm{rec}^{+}\right) / \mathrm{pSU} t d \Delta \operatorname{In} 10 \mathrm{r}$ (3) were lifted onto filters and probed with an intron-specific oligonucleotide (right) (C) Restriction analysis of transductants. The agarose gel shows EcoRI (lanes 1-6) and PvuII (lanes 7-12) digests of pSUtd $\Delta$ In-r DNA (lanes 1,7), pUCtdin ${ }^{+} \mathrm{r}$ (lanes 2,8), and plasmid DNA isolated from transductants hybridizing to the intron probe (lanes 3-6,9-12). (V) Vector bands. (Below) An EcoRI (E) and PvuII (P) restriction map of $t d \mathrm{In}^{+}$and $t d \Delta \mathrm{In}$ inserts. rying the $\mathrm{Kan}^{\mathrm{R}}$ intron donor and Red functions on independent plasmids. In the presence of both red genes, but not red $\alpha$ or $\operatorname{red} \beta$ alone, an $\sim 40$-fold stimulation in the number of $\mathrm{Cam}^{\mathrm{R}}$ transformants was observed over red $^{-}$ controls (Fig. 7B). Faithful intron inheritance was verified in different ways. First, the recipient was linearized with $N c o$, which cleaves outside the region of $t d$ homology. In this case, no stimulation of intron transfer was observed, indicating that homing is dependent on a DSB in the region of homology between donor and recipient (Fig. 7B). Second, isolation of DNA from the Cam ${ }^{\mathrm{R}}$ transformants and retransformation always resulted in $\operatorname{Kan}^{\mathrm{R}}$ and $\mathrm{Cam}^{\mathrm{R}}$ coinheritance, indicating that repair of the DSB in the recipient plasmid is associated with acquisition of the $\mathrm{Kan}^{\mathrm{R}}$ intron (data not shown). Third, to provide physical verification that intron homing had occurred, $\mathrm{Cam}^{\mathrm{R}}$ transformants were analyzed by polymerase chain reaction (PCR). By use of exon primers bordering the intron insertion site, all transformants tested produced the expected intron-carrying fragment (Fig. 7D, lanes 2-6). A transformant from a control experiment using uncleaved recipient plasmid generated the expected intronless PCR product (Fig. 7D, lane 1). Taken together, these results argue strongly that Exo and
Bet are both necessary and sufficient to mediate DSBdependent intron transfer in $E$. coli.

\section{Role for a $3^{\prime} \rightarrow 5^{\prime}$ exonuclease in gap formation}

The dependence of intron homing on a $5^{\prime} \rightarrow 3^{\prime}$ exonuclease suggests the means for generating $3^{\prime}$ tails as intermediates in recombination (Fig. 1). However, given the eccentric nature of the DSB, the $3^{\prime}$ end of the top strand must also be degraded. Resection must extend beyond the intron-insertion site for repair synthesis to result in intron inheritance by DSBR. The gapping functions are likely to be cellular, because intron transfer occurs in the absence of phage infection when Red functions are expressed. Although RecBC and RecJ are candidate nucleases (Smith 1989), homing was only reduced by $50 \%$ in a recBC genetic background and not at all in a recI background (Fig. 2).

To further examine the involvement of $3^{\prime} \rightarrow 5^{\prime}$ exonuclease activity, we tested the effects of exonuclease-deficient mutants in the gene encoding ExoIII $(x t h A)$ and we retested ExoV $(\operatorname{rec} B C)$. In a modification of the experiment presented in Figure 2, with the recipient phage introduced by infection rather than by induction, we ob- 
Table 2. Plasmids

\begin{tabular}{|c|c|c|c|c|}
\hline Name & Relevant features/use & Replicon $^{a}$ & Drug $^{\mathrm{b}}$ & Source/reference \\
\hline pKTd2 & $\mathrm{ORF}^{+}, t d$ driven by $\lambda p \mathrm{~L}$ & ColEl & Amp & Quirk et al. (1989) \\
\hline $\mathrm{pKTd} \Delta 1-3$ & $\mathrm{ORF}^{-}, t d$ driven by $\lambda p \mathrm{~L}$ & ColE1 & Amp & Quirk et al. (1989) \\
\hline $\mathrm{pUCtd} \operatorname{In}^{+} \mathrm{r}^{\mathrm{c}}$ & $t d \operatorname{In}^{+, \mathrm{d}}$ in $\mathrm{pUC} 19$ & ColE1 & Amp & this work \\
\hline $\mathrm{pSU} t d \Delta \operatorname{In}-\mathrm{r}^{\mathrm{c}}$ & $t d \Delta \operatorname{In}^{\mathrm{d}}$ in $\mathrm{pSU} 8 \Delta B a m \mathrm{HI}^{\mathrm{e}}$ & pA15 & Cam & this work \\
\hline $\mathrm{pSU} t d \Delta \operatorname{In} 10 \mathrm{r}^{\mathrm{c}}$ & $\begin{array}{l}t d \Delta \text { In with } 10 \text {-nucleotide } \\
\text { polylinker, in pSU } 8 \Delta B a m H I\end{array}$ & pA 15 & Cam & this work \\
\hline pSUT4oritd $\Delta \mathrm{In}-\mathrm{r}^{\mathrm{c}, \mathrm{f}}$ & $\begin{array}{l}\text { derivative of pSUtd } t \text { In-r with } \\
\text { T4 replication origin }\end{array}$ & pA15 & Kan & this work \\
\hline pCLtd:: $\operatorname{Kan}^{\mathrm{R}}$ & $\begin{array}{l}\text { intron donor, } \operatorname{Kan}^{\mathrm{R}} \text { gene in } \\
\text { place of } t d \text { intron }\end{array}$ & pSC101 & $\begin{array}{l}\text { Kan } \\
\text { Spc }\end{array}$ & $\begin{array}{l}\text { Bell-Pedersen et al. (1990); this } \\
\text { work }\end{array}$ \\
\hline pBStd::Kan ${ }^{\mathrm{R}}$ & $\begin{array}{l}\text { intron donor, } \operatorname{Kan}^{\mathrm{R}} \text { gene in } \\
\text { place of } t d \text { intron }\end{array}$ & ColEl & $\begin{array}{l}\text { Kan } \\
\text { Amp }\end{array}$ & $\begin{array}{l}\text { Bell-Pedersen et al. (1990); this } \\
\text { work }\end{array}$ \\
\hline pCL1920 & vector for intron or red donor & pSC101 & $\mathrm{Spc}$ & Lerner and Inouye (1990) \\
\hline $\mathrm{pMC7}$ & vector for red functions & ColEl & Tet & Fenton and Poteete (1984) \\
\hline pBSKS & vector for intron donor & ColE1 & Amp & Stratagene \\
\hline pJKKmf ${ }^{-}$ & ColE1 "exclusion" plasmid & ColE1 & Kan & Kirschman and Cramer (1988) \\
\hline
\end{tabular}

aplasmids having any of the three different replication origins are compatible.

${ }^{b}$ Drug resistances are as follows: (Amp) ampicillin; (Cam) chloramphenicol; (Tet) tetracycline; (Kan) kanamycin; (Spc) spectimomycin. ${ }^{\mathrm{c}}$ The $\mathrm{r}$ designation indicates that the $t d$ gene is in antitranscriptional orientation relative to plac to prevent lethal expression of I-TevI.

${ }^{\mathrm{d}}$ EcoRI fragment containing $t d$ gene (Chu et al. 1984).

e Deletion of the BamHI site in recipient plasmids facilitates selection against intron-donor plasmids that contain this site.

'This plasmid is deleted for the 375-bp EcoRI-HindIII interval at the $5^{\prime}$ end of the $t d$ fragment and has the T4 gene 34 tertiary origin on a 404-bp EcoRI-EcoRV fragment from pKK061 in the HpaI-EcoRI interval at the 3 ' end of the $t d$ fragment /Chu et al. 1984; Kreuzer and Alberts 1986).

served a consistent, allele-dependent reduction in $t d$ intron mobility in the $x t h A$ mutants. There was an overall two- to eightfold decrease in mobility (Table 3 , cf. crosses 3 and 4 with cross 1 ), with the deletion mutant causing a consistent seven- to eightfold drop in mobility (Table 3, cross 4). Whereas the $\operatorname{rec} B C$ mutant again exhibited a twofold reduction in homing in this assay (Table 3 , cross 5 ; cf. Fig. 2), mobility was completely abolished in an $x$ thA-recBC double mutant (Table 3 , cross 6 ). Although this result must be interpreted with caution given the potential instability of plasmids in an $x t h A$ recBC background (Bassett and Kushner 1984), these data suggest that mobility is eliminated in the absence of both nucleases. Furthermore, although the results imply that ExoIII and ExoV have redundant functions in the homing process, ExoIII seems to be the more critical activity.

\section{Homing appears independent of I-TevI} and of the nature of the DSB

The ability of the $t d$ intron to be transferred into a recipient cleaved in vitro with I-TevI suggests that the nuclease is not involved in recombination per se (Fig. 7). However, these experiments do not rule out the possibility that I-TevI forms a stable complex with the cleaved recipient and is cotransported into the host cells with the DNA. To address this issue we wished to cleave the target DNA with unrelated restriction enzymes. We also wished to ascertain the effect of differences in the nature of the cleaved ends on homing. We therefore utilized a homing-site variant in which three restriction enzyme sites (BamHI, SmaI, and KpnI) were engineered precisely at the intron-insertion site. In this construct, $t d \Delta \operatorname{In} 10$, the 10-nucleotide polylinker completely inhibits cleavage by I-TevI (Bell-Pedersen et al. 1991). The results in Figure $7 \mathrm{C}$ indicate first that recombination is as efficient when the DSB is made with restriction enzymes as with I-TevI, further arguing against a required role for I-TevI in recombination. Second, intron inheritance was efficient whether the ends were blunt (SmaI) or recessed in the $5^{\prime}(\mathrm{KpnI})$ or $3^{\prime}(\mathrm{BamHI})$ directions, indicating that mobility occurs independently of the nature of the DSB. These latter results are consistent with the requirement for both $5^{\prime} \rightarrow 3^{\prime}$ and $3^{\prime} \rightarrow 5^{\prime}$ exonucleases, activities that are necessary to process the DNA ends into effective recombination substrates.

\section{Discussion}

With the $t d$ intron of phage $\mathrm{T} 4$ as the model system, we have implicated several host- and phage-encoded recombination functions in the intron homing process. These include both recombinases and nucleases, whose activities are consistent with the generation of predicted intermediates in the DSBR pathway for intron inheritance (Fig. 1).

The role of RecA recombinase can be readily understood in terms of the homology requirement of mobility (Quirk et al. 1989). Although both RecA and Bet promote annealing of complementary strands, only RecA is capable of directing strand invasion (Kmiec and Holloman 1981; Muniyappa and Radding 1986). We speculate that the dual requirement for both annealing functions in 


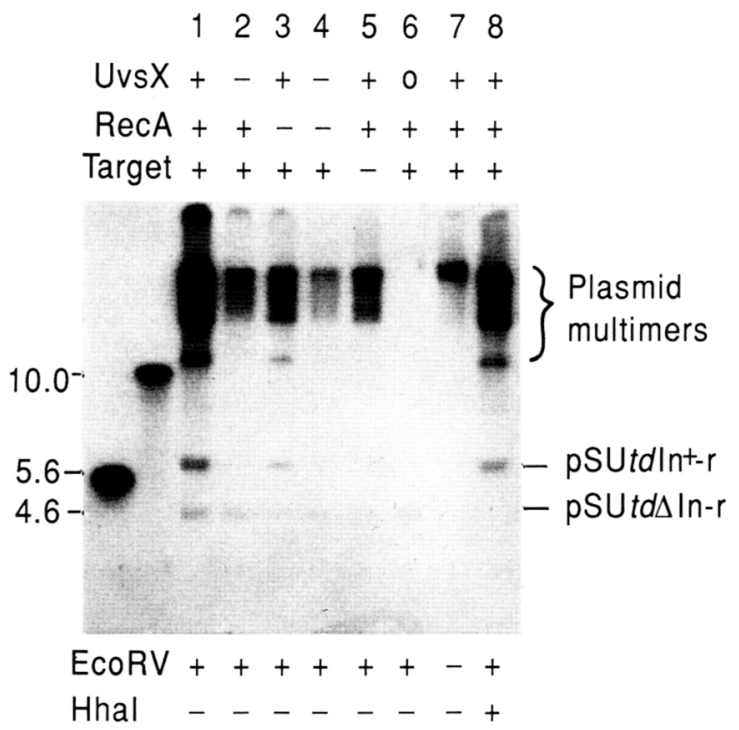

Figure 4. T4 UvsX-dependent intron transfer. Intron transfer was monitored from T4 into recipient plasmid pSUtd $\Delta \mathrm{In}-\mathrm{r}$ with an intact homing site (lanes $1-4,6-8$; target + ) or into pSUtd $\Delta$ In l0r with a disrupted homing site (lane 5; target -1 . The intron donor was T4K10 (lanes $1,3,5,7,8$; UvsX + ) or T4K10uvsX-am 11 (lanes 2,4; UvsX -). DNA in lane 6 was from uninfected cells (UvsX 0). Cells were either RPC8 (lanes 1,2,58; RecA +) or RPC9 (lanes 3,4; RecA -). Total DNA [undigested (lane 7); digested with EcoRV (lanes 1-6); digested with EcoRV and $H$ haI (lane 8 )] was separated on a $0.7 \%$ agarose gel, blotted onto a nitrocellulose filter (Schleicher \& Schuell), and probed with a $0.9-\mathrm{kb}$ intron-specific probe. This probe gave a weak signal with the intron recipient (pSUtdsIn-r), which was present at very high concentration on the stained gel. EcoRV cleaves both modified DNA (T4 DNA, or plasmid replicated in the presence of T4) and unmodified DNA (unreplicated plasmid), whereas Hhal cleaves only unmodified DNA. Plasmid multimers are replication products that appear on the blot as the result of partial EcoRV activity on modified DNA. The two left-most lanes contain size markers. The bands corresponding to the intron recipient and the recombinant are labeled at right.

these experiments resides in the molecular association of Bet with Exo (Muniyappa and Radding 1986), resulting in direct delivery of Bet to the single-stranded tails. Bet may then serve to protect the single strands from nucleolytic cleavage or stimulate joint molecule formation by RecA (Muniyappa and Radding 1986).

Takahashi and Kobayashi (1990) reported a RecA requirement for Red-dependent gap repair in a plasmid carrying inverted repeats. Although these and our results demonstrate a requirement for RecA recombinase, previous work has shown that Red-mediated recombination between phage molecules (Thaler et al. 1987b) or between $\lambda$ and a plasmid carrying homologous DNA (Berg 1971; Thaler et al. 1987a) is RecA independent except under conditions of limited DNA replication. We can reconcile this difference by conjecturing that $\lambda$ recombination is not strictly analogous to Red-mediated intron homing or that intron mobility in this system mimics replication-deficient conditions during $\lambda$ recombination.
The alternative explanation, that the observed RecA-requirement arises from the protection of DSBs (Register and Griffith 1986) generated by I-TevI cleavage rather than from recombinase activity, seems unattractive in view of the requirement for UvsX recombinase function in T4 infection.

The UvsX protein of T4 has both annealing and synaptic activities (Yonesaki et al. 1985; Formosa and Alberts 1986). Predictably, therefore, T4uvs $X^{+}$-infected cells are able to mobilize the $t d$ intron even in a $r e c A^{-}$ background (Figs. 3-5). Interestingly, intron homing is not observed during infection by T4uvs $X^{-}$phage even in a rec $A^{+}$host (Figs. 4 and 5). This result is consistent with previous findings that RecA is inactive in T4-infected cells (Yonesaki and Minagawa 1988) and further supports the role of UvsX in intron homing. The ability of UvsX to assume the role of RecA in intron mobility mirrors its ability to drive $\mathrm{T} 4$ general recombination in the absence of RecA (Mortelmans and Friedberg 1972).

The dependence of intron homing on a $5^{\prime} \rightarrow 3^{\prime}$ nuclease activity (in this case, $\lambda$ Exo) suggests that $3^{\prime}$ tails are requisite intermediates in recombination. The existence of long 3' tails generated during DSBR has been demonstrated recently in yeast (Sun et al. 1991). These tails are essential for break-dependent meiotic recombination. Whereas gap formation in yeast is neither required by the model nor suggested by experiments (Sun et al. 1991), gapping is indicated for $t d$ intron mobility by the DSBR pathway. This requirement arises from the eccentric DSB generated by I-TevI and the need to resect the top strand beyond the intron insertion site to achieve conversion of the intron by DSBR. A role for a $3^{\prime} \rightarrow 5^{\prime}$ exonuclease activity at the DSB is supported by reduced homing in $x$ thA mutants deficient in ExoIII (Table 3). Although ExoIII is a multifunctional enzyme, with AP

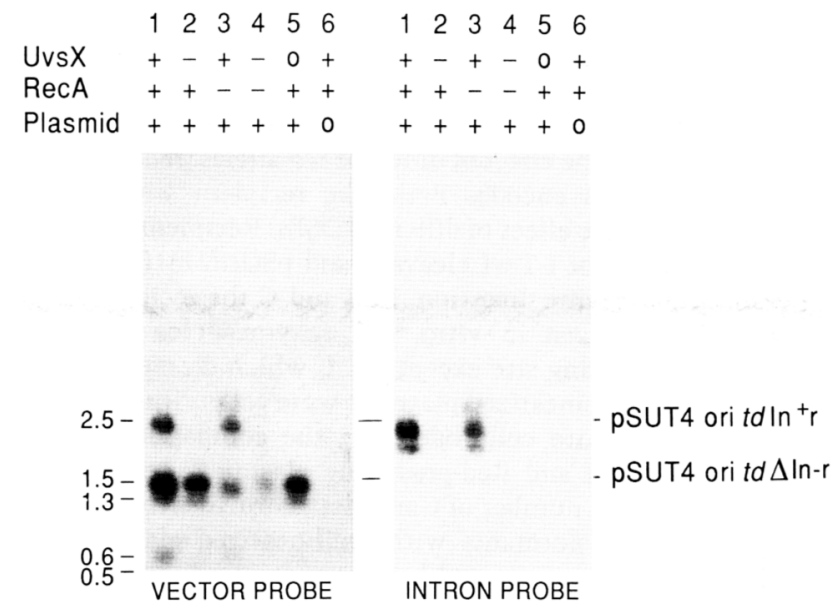

Figure 5. A direct role for UvsX in intron mobility. The experiment was performed as in Fig. 4, except that the recipient pSUT4oritd $\Delta$ In-r contained a T4 replication origin (lanes 1-5). Lanes are labeled $+/-$ as in Fig. $4 ;(0)$ controls with either no phage (lane 5) or no plasmid (lane 6). DNA was digested with SspI and probed with "vector" (pSUT4oritdsIn-r) or intron probes. 
Figure 6. Plasmid-to-plasmid homing with $\lambda$ helper. Cells with intron-donor $(D$, pUCtd $\left.\Delta \operatorname{In}^{+} \mathrm{r}, A m \mathrm{Am}^{\mathrm{R}}\right)$ and recipient (R, pSUtd $\Delta \mathrm{In}-\mathrm{r}, \mathrm{Cam}^{\mathrm{R}}$ ) plasmids were infected in log phase with $\lambda$ helper. Plasmid DNA was extracted and digested with BamHI to select against the donor, and $\mathrm{Cam}^{\mathrm{R}}-\mathrm{Amp}^{\mathrm{S}}$ transformants were probed for the intron. An $\mathrm{ORF}^{-}$control donor (tds1-3) was used in all crosses; the background recombination was $<0.5 \%$ as for cross 3. Each experiment was repeated twice, with $<10 \%$ variation, except for the ared 113 cross, where homing ranged between $1 \%$ and $4.2 \%$. Similar results were obtained with $\lambda$ prophage induction. Cross 2 is isogenic with crosses 3 and 4 , and cross 5 with crosses 6 and 7 (Table 1).

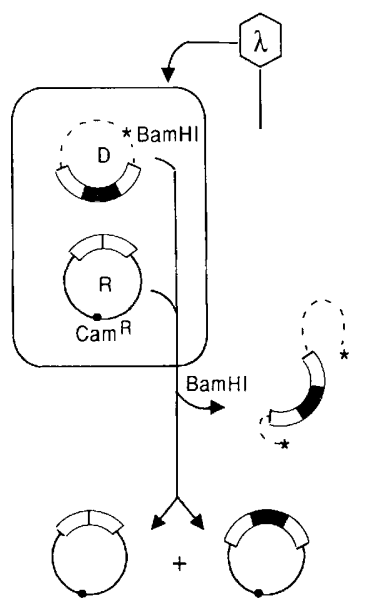

\begin{tabular}{lllllllll}
\hline Cross & Helper & $\begin{array}{c}\text { red } \\
\text { ORF }\end{array}$ & $\begin{array}{c}\text { Total } \\
\text { colonies }\end{array}$ & $\begin{array}{c}\text { Intron } \\
\text { plus }\end{array}$ & $\begin{array}{c}\% \\
\text { Homing }\end{array}$ \\
\cline { 1 - 4 } 1 & None & - & - & + & 208 & 1 & $<0.5$ \\
2 & $\lambda^{+}$ & + & + & + & 326 & 61 & 18.7 \\
3 & $\lambda^{+}$ & + & + & - & 260 & 1 & $<0.5$ \\
4 & $\lambda$ bio10 & - & - & + & 311 & 0 & $<0.5$ \\
5 & $\lambda^{+}$ & + & + & + & 148 & 29 & 19.7 \\
6 & $\lambda$ b2141 & - & + & + & 487 & 8 & 1.6 \\
7 & $\lambda$ red113 & + & - & + & 423 & 18 & 4.2
\end{tabular}

endonuclease, 3'-phosphatase, and RNase $\mathrm{H}$ activities (Linn 1985), it seems logical that the observed reduction in homing efficiency is attributable to its $3^{\prime} \rightarrow 5^{\prime}$ exonuclease activity. Furthermore, RecBC nuclease appears to provide a redundant exonuclease activity. Although rec $B C$ - $x$ th $A$ double mutants cannot support intron homing (Table 3), an auxiliary role for other $E$. coli $3^{\prime} \rightarrow 5^{\prime}$ exonucleases (Kornberg and Baker 1991) remains a possibility.

Further support for gap formation preceding $3^{\prime}$-tail invasion is provided by $100 \%$ coconversion of markers between the $t d$ intron-insertion site and the cleavage site (Bell-Pedersen et al. 1989, 1990). Moreover, the observation that intron transfer is independent of the nature of the DSB $\mid 3^{\prime}$ or $5^{\prime}$ extensions or blunt ends; Fig. $7 \mid$, par- ticularly given that the cut occurs within the short stretch of heterology created by the linker insertion in $t d \Delta \operatorname{In} 10$, suggests that $3^{\prime} \rightarrow 5^{\prime}$ exonucleolytic activity plays a general role in this recombination pathway in $E$. coli, rather than being confined to meeting the specific needs of $t d$ intron homing.

The requirement for gap formation in $t d$ intron transfer suggests that different molecular events may account for the observed coconversion of flanking markers during DSBR in the $E$. coli/phage system and in yeast. In the absence of gap formation in the eukaryotic system, coconversion would result from mismatch repair of heteroduplex DNA. In contrast, when gap formation occurs, as in the prokaryotic system, coconversion would have to result, at least in part, directly from gap repair.
Figure 7. Three-plasmid mobility system. (A) Schematic of the system. The recipient plasmid (R) was cleaved in vitro and delivered to cells containing the $\mathrm{Kan}^{\mathrm{R}}$ donor plasmid (D) and the third plasmid supplying Red functions. Arrows represent exon primers used for PCR analysis. (B) The effect of different red alleles (red $\alpha$ encodes Exo; red $\beta$ encodes Bet). The recipient was pSUtd $\Delta$ In-r. (C) The effect of different DSBs. Recipients were pSUtdsIn-r for I-TevI cleavage and pSUtd $\Delta$ In 10r for restriction enzyme digestion. In $B$ and $C$ the recipients were linearized in vitro. All enzymes cleave within the $t d$ homing site except $N c o$, which cleaves vector sequences. Linearized plasmids were gel purified and transformed into cells harboring the compatible $\mathrm{Kan}^{\mathrm{R}}$ intron donor and Red-producing plasmids. Percent homing is the number of $\mathrm{Cam}^{\mathrm{R}}$ transformants relative to total transformants with nonlinearized plasmids. Plasmids were extracted from transformants and retransformed to confirm coinheritance of $\mathrm{Kan}^{\mathrm{R}}$ and Cam ${ }^{\mathrm{R}}$ markers. $(D)$ Verification of intron inheritance of $\mathrm{Cam}^{\mathrm{R}}$ transformants by PCR. Exon-specific primers (see $A$ ) are predicted to generate products of 195 and $1505 \mathrm{bp}$ for $\mathrm{In}^{-}$and $\mathrm{In}^{+}$alleles, respectively. PCR templates were the recipient plasmid (lane 1) and five $\mathrm{Cam}^{\mathrm{R}}$ transformants (lanes 2-6). Lanes 7 and 8 contain DNA size markers.

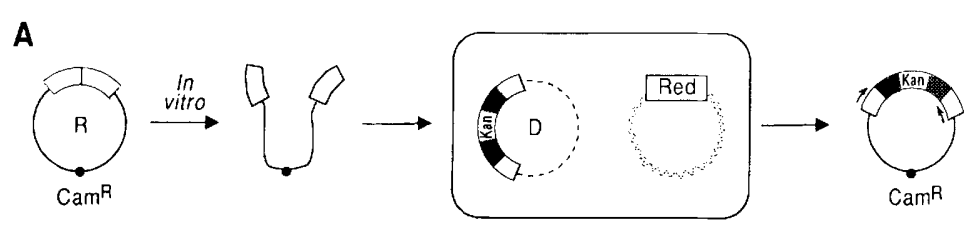

B

\begin{tabular}{cccc}
\hline \multicolumn{2}{c}{ red } & \multicolumn{2}{c}{$\%$ Homing } \\
$\alpha$ & $\beta$ & I-TevI & Ncol \\
\hline- & - & 0.31 & 0.30 \\
+ & - & 0.25 & 0.22 \\
- & + & 0.40 & 0.51 \\
$+\quad+$ & 11.75 & 0.06
\end{tabular}

C

\begin{tabular}{lcr}
\hline \multirow{2}{*}{ Enzyme } & \multicolumn{2}{c}{$\%$ Homing } \\
& Red $^{+}$ & Red $^{-}$ \\
\hline I-Tevl & 3.3 & $<0.3$ \\
Kpnl & 7.5 & $<0.3$ \\
Smal & 4.7 & $<0.3$ \\
Bam $\mathrm{H} \mid$ & 4.8 & $<0.3$ \\
Ncol & $<0.1$ & $<0.3$
\end{tabular}

D

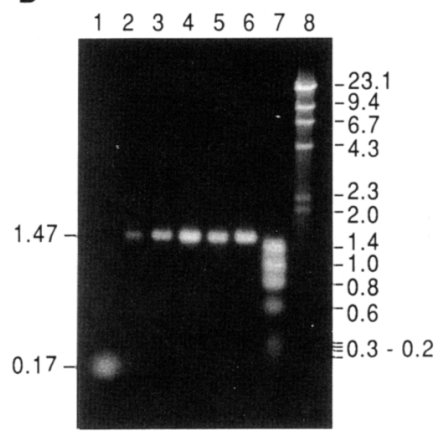


Table 3. A role for ExolII in intron homing

\begin{tabular}{|c|c|c|c|c|c|c|c|}
\hline \multirow[b]{2}{*}{ Cross } & \multicolumn{2}{|c|}{ Genotype } & \multirow[b]{2}{*}{ Strain } & \multirow[b]{2}{*}{ ORF } & \multirow[b]{2}{*}{ Plaques scored } & \multirow[b]{2}{*}{ In $^{+}$plaques } & \multirow[b]{2}{*}{$\operatorname{In}^{+}(\%)^{\mathrm{a}}$} \\
\hline & $\operatorname{rec} B C$ & $x \operatorname{th} A$ & & & & & \\
\hline 1 & + & + & $\mathrm{AB} 1157$ & + & 650 & 155 & 23.8 \\
\hline 2 & + & + & $\mathrm{AB} 1157$ & - & 469 & 8 & 1.7 \\
\hline 3 & + & $-{ }^{b}$ & SK1314 & + & 913 & 93 & 10.2 \\
\hline 4 & + & $-c$ & BW9109 & + & 226 & 7 & 3.1 \\
\hline 5 & - & + & JC5519 & + & 517 & 50 & 9.7 \\
\hline 6 & - & $-b$ & SK1733 & + & 999 & 1 & 0.1 \\
\hline
\end{tabular}

Percent $\mathrm{In}^{+}$was determined as in Fig. 2, except that the recipient phage was introduced by infection at $37^{\circ} \mathrm{C}$ in this experiment. Each cross was repeated at least twice.

${ }^{\mathrm{b}}$ The $x$ th $A 1$ allele is present in these strains.

${ }^{\mathrm{c}}$ The $\Delta x \operatorname{th} A$ allele is present in this strain.

All of seven characterized endonucleases encoded by mobile introns in prokaryotes and eukaryotes generate DSBs with $3^{\prime}$ extensions 2-4 nucleotides in length (for review, see Clyman et al. 1992). In contrast, endonuclease I-TevIII, encoded by the $n r d \mathrm{~B}$ intron of $\mathrm{T}$-even phage RB3, cleaves the $\mathrm{In}^{-}$target to yield $5^{\prime}$ extensions (Eddy and Gold 1991). Interestingly, attempts to demonstrate mobility of this intron have failed, suggesting a possible link between the nature of the cleaved DNA ends and the ability to undergo recombination. However, the results presented here demonstrate efficient intron inheritance whether the DSB has $3^{\prime}$ or $5^{\prime}$ extensions or blunt ends, arguing against a correlation between a $3^{\prime}$ extension and the ability to undergo recombination. Furthermore, intron conversion occurred readily regardless of whether the DSB was precisely at the intron insertion site or displaced from the site, as long as cleavage occurred within stretches of homology between donor and recipient. These experiments suggest that neither the nature of the DSB nor its precise location within homologous sequences is a major determinant in the mobility process.

The three-plasmid mobility experiment, in which the recipient was cleaved in vitro with I-TevI or with restriction enzymes, indicates that I-TevI is not required for recombination beyond generating the DSB (Fig. 7). Similarly in the case of the artificial intron constructed by Eddy and Gold (1992), EcoRI was able to serve as the mobilizing nuclease. This situation is in contrast to that with classical transposases, which cleave their DNA substrates and are subsequently involved in the formation and resolution of recombination intermediates (Berg and Howe 1989). These variations parallel differences in the cis requirements of these different classes of mobile elements: Transposition requires the transposase to act at specific sequences at the transposon termini to promote DNA cleavage and strand exchange (Berg and Howe 1989), whereas intron homing occurs independently of any intron sequences (Bell-Pedersen et al. 1990), requiring only a DSB and exon homology.

These studies open the way for determining how T4 satisfies all of the requirements for mobilizing its introns. It remains unclear which $\mathrm{T} 4$ functions substitute for the $\lambda$ Red system and provide the necessary $5^{\prime} \rightarrow 3^{\prime}$ nuclease and associated annealing activities, although the products of genes 46 and 47 , which form a nuclease complex, are likely candidates. Regardless, $\mathrm{T} 4$ will have had to participate in the acquisition of its complement of mobile introns beyond providing UvsX because, clearly, wild-type $E$. coli is incapable of supplying all requisite functions. In this regard, it is noteworthy that no mobile introns have yet been reported in uninfected eubacterial cells. This raises the possibility that the spread of introns throughout bacterial populations is impeded by the inability of these cells to potentiate efficient double-strand gap repair except under specific genetic conditions (Smith 1989). Mobile introns would therefore be confined to phages that have the recombinational accessories to incorporate these elements into DSBs within their genomes. Likewise, transfer of mobile introns across species lines (Dujon 1989; Lambowitz 1989) would depend on the requirements for recombination being met by the new host organism.

\section{Materials and methods}

Strains and plasmids

Bacterial and phage strains are listed in Table 1, and plasmids are listed in Table 2.

\section{Screening host mutants for intron mobility}

The intron recipient $\lambda$ gtlltd $\Delta$ In (Quirk et al. 1989) has a thermolabile repressor and the Sam 100 mutation, preventing cell lysis in nonsuppressing hosts. Lysogens containing donor plasmid were grown at $30^{\circ} \mathrm{C}$ in TBYET $(1 \%$ tryptone, $0.5 \%$ yeast extract, $0.5 \% \mathrm{NaCl}, 50 \mu \mathrm{g} / \mathrm{ml}$ of thymine) with ampicillin (200 $\mu \mathrm{g} / \mathrm{ml}$ ) to $2 \times 10^{8}$ cells $/ \mathrm{ml}$. All cultures were thermoinduced for $15 \mathrm{~min}$ at $44^{\circ} \mathrm{C}$ and transferred to $37^{\circ} \mathrm{C}$ for $4-6 \mathrm{hr}$ with shaking. Cultures were lysed with chloroform, and lysates were harvested by centrifugation and titered on a supF host (Ymel). Plaque lifts and hybridization with an intron-specific probe were as described previously (Quirk et al. 1989). An aliquot of each culture was removed immediately before induction and in experiments where mobility was not observed; for example, in a recA200 host, plasmid-borne ORF expression was tested by 
transforming $\mathrm{N} 99(\lambda c \mathrm{I857)}$ and monitoring intron mobility into T2L (Quirk et al. 1989).

For testing intron homing by phage infection, the intron donor was pUCtdIn ${ }^{+} \mathrm{r}$. Transformants $\left\{5 \times 10^{8}\right.$ cells $\rangle$ were plated in top agar on TB plates, and 2- $\mu$ l dilutions of $\lambda t d \Delta \operatorname{In} S^{+}$, a spontaneous $S^{+}$revertant of $\lambda g t 11 t d \Delta \mathrm{In}$, were spotted on the bacterial lawn and incubated overnight at $37^{\circ} \mathrm{C}$. Clearings from the highest dilution that produced confluent lysis were scraped into $\mathrm{TM}$ (10 $\mathrm{mM}$ Tris at $\left.\mathrm{pH} 7.4,10 \mathrm{mM} \mathrm{MgCl}_{2}\right)$ saturated with chloroform. Intron inheritance by progeny phage was tested as described above.

\section{T4 transduction}

T4-mediated plasmid transduction was performed as described by Kreuzer and Alberts (1986), except that stationary-phase cultures of $E$. coli $\mathrm{B}$ were used as the $\mathrm{Su}^{0}$ transduction host (Fig. 3). $\mathrm{Su}^{+}$transformants containing the intron recipient plasmid pSUtd $\Delta I n-\mathrm{r}\left(\mathrm{Cam}^{\mathrm{R}}\right.$; Table 2) were infected with T4K10, which has amber mutations in the capsid-processing proteins 38 and 51 and mutations in $\operatorname{den} A$ and $\operatorname{den} B$ to prevent plasmid degradation (Selick et al. 1988). Alternatively, plasmid pSUtdDIn 10r with a disrupted homing site was used. Progeny phage were then infected into a $\mathrm{Su}^{\circ}$ host so that only cells that inherited transduced plasmid DNA from defective phage would grow on chloramphenicol plates. $\mathrm{Cam}^{\mathrm{R}}$ transductants were then lifted onto filters and probed with an intron-specific oligonucleotide (Quirk et al. 1989).

\section{Southern analysis of intron transfer from T4} to a plasmid recipient

Cells containing a $t d \Delta$ In recipient plasmid were grown in TBYET to an $\mathrm{OD}_{650}$ of 0.2 and infected with $\mathrm{T} 4 \mathrm{~K} 10$ derivatives at an m.o.i. of 4 . After incubation at $37^{\circ} \mathrm{C}$ for $1 \mathrm{hr}$ with aeration, total DNA was extracted according to Kreuzer et al. (1988a), except that DNA was concentrated on a spin column ultrafilter (Centricon-100) instead of being dialyzed. DNA yields were $\sim 250 \mathrm{ng} / \mu \mathrm{l}$ in a total volume of $50-100 \mu \mathrm{l}$. DNAs $(0.5-\mathrm{l} \mu \mathrm{g})$ were restricted and subjected to Southern hybridization. The probes were a random primer-labeled $0.9-\mathrm{kb} A c c \mathrm{I}-P_{V u I I}$ intron fragment (for map, see Chu et al. 1984) or the intronless recombinant pSUT4oritdsIn-r.

\section{Plasmid-to-plasmid homing with phage $\lambda$ helper}

C600 (thi, thr, leu, lacY, tonA, supE44, $\mathrm{F}^{-}$) cells were transformed with intron recipient pSUtd $\Delta$ In-r and intron donor pUCtdIn ${ }^{+}$. The unique BamHI site in the recipient was removed by linearization with $B a m H I$ and Klenow fill-in. Overnight cultures were diluted $1: 50$ into fresh TBYET media containing ampicillin $(200 \mu \mathrm{g} / \mathrm{ml})$ and chloramphenicol $(25 \mu \mathrm{g} / \mathrm{ml})$ and grown to $2 \times 10^{8}$ cells $/ \mathrm{ml}$. Aliquots of $5 \mathrm{ml}$ were harvested by centrifugation, resuspended in $0.2-0.5 \mathrm{ml}$ of TM containing $1 \times 10^{9} \lambda \mathrm{Sam} 7$ derivatives (Table 1 ), and incubated for $15 \mathrm{~min}$ at $30^{\circ} \mathrm{C}$ to allow phage adsorption. The infected cells were added to $10 \mathrm{ml}$ of fresh TBYET and incubated with shaking for 4-5 hr at $38^{\circ} \mathrm{C}$. Aliquots were removed, and plasmid DNA was isolated, while the remaining culture was lysed with $\mathrm{CHCl}_{3}$ and titered to monitor for successful infection (generally $>10^{9}$ phage $/ \mathrm{ml}$ ). DNAs were treated with BamHI before transformation to inactivate intron donor DNA for transformation. The retransformation host RRI harbored a ColEl replicon ( $\mathrm{pJKKmf}^{-}$) to further block cotransformation of the intron donor plasmid. To confirm that $\mathrm{Cam}^{\mathrm{R}}$ transformants did not coinherit the pUCt $d$ donor, transformants were either plated in parallel onto ampicillin plates or replica-plated to check for $\mathrm{Amp}^{\mathrm{s}}$ colonies. $\mathrm{Cam}^{\mathrm{R}}$ transformants were probed for intron inheritance as described previously (Quirk et al. 1989).

\section{Red-dependent three-plasmid mobility system}

The intron recipient plasmid was linearized in vitro by I-TevI in the case of pSUtd In-r or by a restriction enzyme in the case of pSUtdaInl0r, which contains a 10-nucleotide $\left(5^{\prime}\right.$-ACCCGGGATC- $3^{\prime}$ ) restriction site polylinker (KpnI, SmaI, BamHI) at the intron-insertion site. Linearized plasmids were gel purified, and equal amounts were transformed (Inoue et al. 1990) into cells harboring the compatible $\mathrm{Kan}^{\mathrm{R}}$-marked intron donor and Redproducing plasmids. IPTG $(100 \mu \mathrm{g} / \mathrm{ml})$ was added at an $\mathrm{OD}_{600}$ of 0.4 to induce the Red functions before making cells competent. The intron donor was either on pCL1920 (pCLtd::Kan ${ }^{\mathrm{R}}$ ), with Red functions supplied from pMC7 (Fenton and Poteete 1984), or on pBSKS (pBStd::Kan ${ }^{\mathrm{R}}$ ), with Red functions supplied from pCL1920 (Lerner and Inouye 1990).

\section{Acknowledgments}

We appreciate productive discussions with $\mathrm{K}$. Kreuzer, who provided several critical suggestions. We thank D. Bell-Pedersen, M. Bryk, D. Monroe, and M. Parker for technical help, M. Bryk, T. Coetzee, N. Loizos, J. Mueller, and M. Parker for useful comments on the manuscript, and M. Carl and C. Wieland for preparing the manuscript. We also thank D. Bousset, J. Clark, D. Court, R. Cunningham, L. Enquist, D. Friedman, M. Inouye, R. Kolodner, K. Kreuzer, S. Kushner, D. Mount, N. Ossanna, T. Poteete, M. Simon, A. Skalka, and D. Wulff for providing strains. Work was supported by National Institutes of Health grants GM39422 and GM44844 to M.B. and GM13866 to J.C.

The publication costs of this article were defrayed in part by payment of page charges. This article must therefore be hereby marked "advertisement" in accordance with 18 USC section 1734 solely to indicate this fact.

\section{References}

Bassett, C.L. and S.R. Kushner. 1984. Exonuclease I, III, and V are required for stability of ColEl-related plasmids in Escherichia coli. J. Bacteriol. 157: 661-664.

Belfort, M. 1990. Phage T4 introns: Self-splicing and mobility. Annu. Rev. Genet. 24: 363-385.

Bell-Pedersen, D., S. Quirk, M. Aubrey, and M. Belfort. 1989. A site-specific endonuclease and coconversion of flanking exons associated with the mobile $t d$ intron of phage T4. Gene 82: 119-126.

Bell-Pedersen, D., S. Quirk, J. Clyman, and M. Belfort. 1990. Intron mobility in phage $\mathrm{T} 4$ is dependent upon a distinctive class of endonucleases and independent of DNA sequences encoding the intron core: Mechanistic and evolutionary implications. Nucleic Acids Res. 18: 3763-3770.

Bell-Pedersen, D., S.M. Quirk, M. Bryk, and M. Belfort. 1991. I-TevI, the endonuclease encoded by the mobile $t d$ intron, recognizes binding and cleavage domains on its DNA target. Proc. Natl. Acad. Sci. 88: 7719-7723.

Berg, D.E. 1971. Regulation in phage with duplications of the immunity region. In The bacteriophage lambda (ed. A.D. Hersheyl, pp. 667-678. Cold Spring Harbor Laboratory, Cold Spring Harbor, New York.

Berg, D.E. and M.M. Howe. 1989. Mobile DNA, pp. 23-52, 163184, 227-268. American Society for Microbiology, Washington, D.C. 
Bousset, R.B. and M.S. Fox. 1988. Lysogenization of Escherichia coli him ${ }^{+}$, himA, and himD hosts by bacteriophage $\mathrm{Mu} . J$. Bacteriol. 170: 1672-1682.

Chu, F.K., G.F. Maley, F. Maley, and M. Belfort. 1984. Intervening sequence in the thymidylate synthase gene of bacteriophage T4. Proc. Nat1. Acad. Sci. 81: 3049-3053.

Clyman, J., S. Quirk, and M. Belfort. 1992. Mobile introns in the T-even phages. In The molecular biology of bacteriophage T4 (ed. J. Karam) American Society for Microbiology, Washington, D.C. (In press.)

Dujon, B. 1989. Group I introns as mobile genetic elements: Facts and mechanistic speculations-A review. Gene 82: 91114.

Dujon, B., M. Belfort, R.A. Butow, C. Jacq, C. Lemieux, P.S. Perlman, and B.M. Vogt. 1989. Mobile introns: Definition of terms and recommended nomenclature. Gene 82: 115-118.

Eddy, S.R. and L. Gold. 1991. The phage T4 nrdB intron: A deletion mutant of a version found in the wild. Genes \& Dev. 5: 1032-1041.

1992. Artificial mobile DNA element constructed from the EcoRI endonuclease gene. Proc. Natl. Acad. Sci. 89: 1544-1547.

Fenton, A.C. and A.R. Poteete. 1984. Genetic analysis of the erf region of the bacteriophage P22 chromosome. Virology 134: 148-160.

Fishel, R. and R. Kolodner. 1989. Gene conversion in Escherichia coli: The RecF pathway for resolution of heteroduplex DNA. I. Bacteriol. 171: 3046-3052.

Formosa, T. and B.M. Alberts. 1986. Purification and characterization of the T4 bacteriophage uvsX protein. J. Biol. Chem. 261: 6107-6118.

Henderson, D. and J. Weil. 1975. Recombination-deficient deletions in bacteriophage $\lambda$ and their interaction with chi mutations. Genetics 79: 143-174.

Inoue, H., H. Nojima, and H. Okayama. 1990. High efficiency transformation of Escherichia coli with plasmids. Gene 96: $23-28$.

Johnson, R.C., C.A. Ball, D. Pfeffer, and M.I. Simon. 1988. Isolation of the gene encoding the Hin recombinational enhancer binding protein. Proc. Natl. Acad. Sci. 85: 3484 3488.

Kirschman, J.A. and J.H. Cramer. 1988. Two new tools: Multipurpose cloning vectors that carry kanamycin or spectinomycin/streptomycin resistance markers. Gene 68: 163-165.

Kmiec, E. and W.K. Holloman. 1981. Beta protein of bacteriophage $\lambda$ promotes renaturation of DNA. I. Biol. Chem. 256: $12636-12639$.

Kornberg, A. and T.A. Baker. 1991. DNA replication. W.H. Freeman and Company, New York.

Kreuzer, K.N. and B.M. Alberts. 1986. Characterization of a defective phage system for the analysis of bacteriophage T4 DNA replication origins. I. Mol. Biol. 188: 185-198.

Kreuzer, K.N., H.W. Engman, and W.Y. Yap. 1988a. Tertiary initiation of replication in bacteriophage T4. J. Biol. Chem. 263: 11348-11357.

Kreuzer, K.N., W.Y. Yap, A.E. Menkens, and H.W. Engman. 1988b. Recombination-dependent replication of plasmids during bacteriophage T4 infection. I. Biol. Chem. 263: 11366-11373.

Lambowitz, A.M. 1989. Infectious introns. Cell 56: 323-326.

Lerner, C.G. and M. Inouye. 1990. Low copy number plasmids for regulated low-level expression of cloned genes in Escherichia coli with blue/white insert screening capability. $\mathrm{Nu}$ cleic Acids Res. 18: 4631.

Linn, S. 1985. The deoxyribonucleases of Escherichia coli. In Nucleases (ed. S. Linn and R. Roberts), pp. 291-310. Cold
Spring Harbor Laboratory, Cold Spring Harbor, New York.

Michel, F. and B. Dujon. 1986. Genetic exchanges between bacteriophage T4 and filamentous fungi? Cell 46: 323.

Mortelmans, K. and E.C. Friedberg. 1972. Deoxyribonucleic acid repair in bacteriophage T4: Observation on the role of the $x$ and $y$ genes and of host factors. J. Virol. 10: 730-736.

Muniyappa, K. and C.M. Radding. 1986. The homologous recombination system of phage lambda. $J$. Biol. Chem. 261: 7472-7478.

Oppenheim, A.O. and D. Court. 1983. Phage lambda's accessory genes. In Lambda II (ed. R.W. Hendrix, J.W. Roberts, F.W. Stahl, and R.A. Weisbergl, pp. 251-277. Cold Spring Harbor Laboratory, Cold Spring Harbor, New York.

Perlman, P.S. and R.A. Butow. 1989. Mobile introns and intronencoded proteins. Science 246: 1106-1109.

Quirk, S.M., D. Bell-Pedersen, and M. Belfort. 1989. Intron mobility in the T-even phages: High frequency inheritance of group I introns promoted by intron open reading frames. Cell 56: $455-465$.

Register, J.C. and J. Griffith. 1986. RecA protein filaments can juxtapose DNA ends: An activity that may reflect a function in DNA repair. Proc. Natl. Acad. Sci. 83: 624-628.

Selick, H.E., K.N. Kreuzer, and B.M. Alberts. 1988. The bacteriophage $\mathrm{T} 4$ insertion/substitution vector system. A method for introducing site-specific mutations into the virus chromosome. I. Biol. Chem. 263: 11336-11347.

Shulman, M.J., L.M. Hallick, H. Echols, and E.R. Signer. 1970. Properties of recombination-deficient mutants of bacteriophage lambda. J. Mol. Biol. 52: 501-520.

Smith, G.R. 1989. Homologous recombination in E. coli: Multiple pathways for multiple reasons. Cell 58: 807-809.

Sun, H., D. Treco, and J.W. Szostak. 1991. Extensive 3'-overhanging, single-stranded DNA associated with the meiosisspecific double-strand breaks at the ARG4 recombination initiation site. Cell 64: 1155-1161.

Szostak, J.W., T.L. Orr-Weaver, R.J. Rothstein, and F.W. Stahl. 1983. The double-strand-break repair model for recombination. Cell 33: 25-35.

Takahashi, N. and I. Kobayashi. 1990. Evidence for the doublestrand break repair model of bacteriophage $\lambda$ recombination. Proc. Natl. Acad. Sci. 87: 2790-2794.

Thaler, D.S., M.M. Stahl, and F.W. Stahl. 1987a. Tests of the double-strand-break repair model for red-mediated recombination of phage $\lambda$ and plasmid $\lambda \mathrm{dv}$. Genetics 116: 501-511.

Thaler, D.S., M.M. Stahl, and F.W. Stahl. 1987b. Double-chaincut sites are recombination hotspots in the Red pathway of phage $\lambda$. J. Mol. Biol. 95: 75-87.

Walker, G. 1984. Mutagenesis and inducible responses to deoxyribonucleic acid damage in Escherichia coli. Microbiol. Rev. 48: 60-93.

Wilson, G.G., K.K.Y. Young, G.J. Edlin, and W. Konigsberg. 1979. High-frequency generalized transduction by bacteriophage T4. Nature 280: 80-81.

Yonesaki, T. and T. Minagawa. 1988. In vitro and in vivo recombination-related reactions of Escherichia coli recA protein and glycosyl-hydroxymethyl-deoxycytidine DNA. Mol. Gen. Genet. 213: 548-550.

Yonesaki, T., Y. Ryo, T. Minagawa, and H. Takahashi. 1985. Purification and some of the functions of the products of bacteriophage T4 recombination genes, uvsX and uvsY. Eur. J. Biochem. 148: 127-134. 


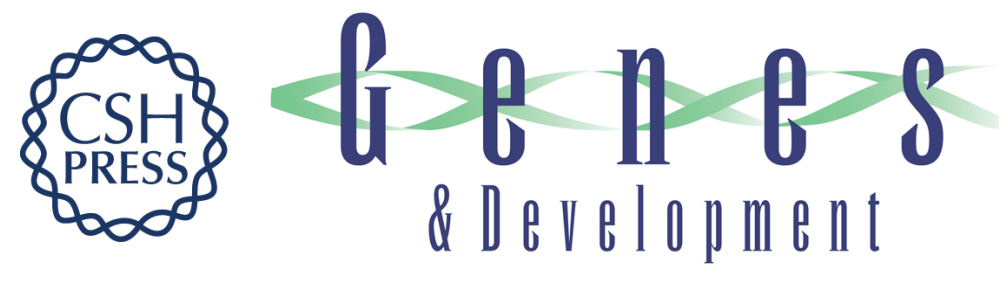

\section{Trans and cis requirements for intron mobility in a prokaryotic system.}

$\mathrm{J}$ Clyman and $\mathrm{M}$ Belfort

Genes Dev. 1992, 6:

Access the most recent version at doi:10.1101/gad.6.7.1269

References This article cites 42 articles, 20 of which can be accessed free at: http://genesdev.cshlp.org/content/6/7/1269.full.html\#ref-list-1

License

Email Alerting

Service

Receive free email alerts when new articles cite this article - sign up in the box at the top right corner of the article or click here.

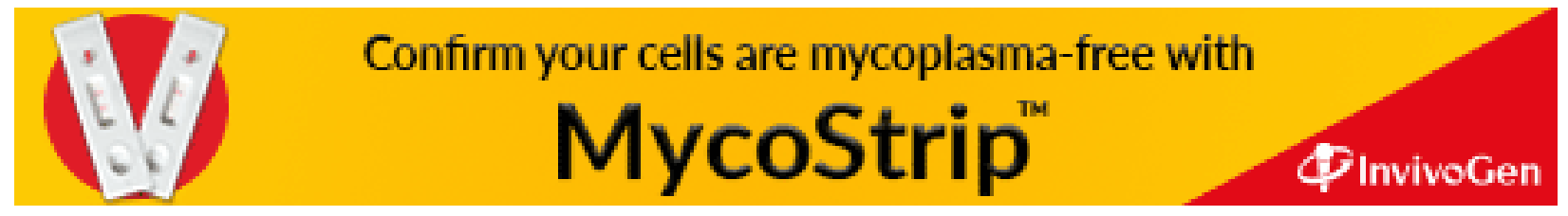

